\title{
Determining the Gas Concentration and Overpressure Magnitude of an Ammonia Refrigerant Explosion
}

\author{
Jihoon Kim \\ Department of Safety Engineering, Graduate School of Seoul, \\ University of Science and Technology, 809 Technocube, 232 Gongneung-ro, \\ Nowon-gu, Seoul, Republic of Korea, rmcgood@krmc.kr, +82-10-3277-1763
}

\begin{abstract}
Ammonia gas is toxic and flammable and exposure to ammonia can cause eye irritation, headaches, and dyspnea in humans. There is a common misconception that the pungency of ammonia makes it easy to identify even the smallest leak and that its relatively high flammability limit allows for simple, quick safety measures to avoid fire or explosion. However, on February, 13, 2014, ammonia gas used as a refrigerant in a high-pressure gas refrigeration facility in Namyangju-si, Gyeonggi-do exploded. This accident resulted in significant academic and industrial interest in the hazards of ammonia gas explosions. Although, ammonia gas leaks do not typically reach the explosion limit concentration because it is lighter than air and thus easily dispersed, if the gas leaks into a confined or poorly ventilated space, the explosion limit can be easily attained and the presence of an ignition source can then result in an explosion. To determine the nature of the explosion hazard presented by ammonia gas, this study evaluated the behavior and explosion potential of an ammonia gas leak accounting for the leakage and dispersion conditions of the February, 2014 explosion. To determine the likely concentrations of gas, the overpressure blast waves resulting from the upper and lower limits of the explosion range were determined by PHAST Software simulation and compared to observed damage from the February, 2014 explosion. The overpressure resulting from the explosion of gas at the upper explosion limit, achieved as the concentration of gas was reduced into the explosion range during an attempt to vent the leaked ammonia gas was determined to have been capable of inflicting the observed damage, providing a general understanding of the process that led to the explosion and informing several proposals to mitigate the risk of ammonia explosions in the future.
\end{abstract}

Key words: Ammonia gas, refrigerant, gas concentration, explosion limit, determine, PHAST Software

\section{INTRODUCTION}

A refrigerant is the working fluid that serves as a core component of refrigeration or freezing equipment. In a freezer, the refrigerant absorbs heat from a low-temperature heat source then transmits and discharges it to a high-temperature heat source. The freezing process consists of the iteration of refrigerant evaporation (from liquid to gas) and condensation (from gas to liquid) processes, occurring as the result of the absorption and discharge, respectively of heat by the refrigerant. Because ammonia gas satisfies almost all the thermophysical requirements for a good refrigerant, it has been the most commonly used refrigerant in large-capacity freezers, typically used for industrial ice making and food storage, from the beginning.

Though ammonia gas is toxic and flammable because it has a pungent smell and an explosive limit range from a Lower Explosive Limit (LEL) of 15\% to an Upper Explosive Limit (UEL) of $28 \%$ by volume in air (higher than most other flammable gases), some gas experts have a misconception that even the slightest ammonia release can be easily and safely detected, allowing operators to respond quickly to avoid damage, rarely resulting in fire or explosion.

However, an ammonia gas leak caused an explosion on February, 13, 2014 at a refrigeration facility located in Namyangju-si, Gyeonggi-do, causing the partial collapse of a warehouse structure as shown in Fig. 1. Ammonia gas was confirmed as the cause of the explosion from the carbonization of the surface of the thermal insulator of the refrigerant pipe installed inside the quick freezer as well as the fact that the four walls of the freezer had been blown outwards. Three employees of the refrigeration facility were injured by the explosion and one employee working in the warehouse adjacent to the freezer was killed. Additionally, a 14.5 ton liquid nitrogen tank was dislodged and fell to the ground. Furthermore, unburned ammonia gas was dispersed in the surrounding area which contained stores and houses, causing people to 
(a)

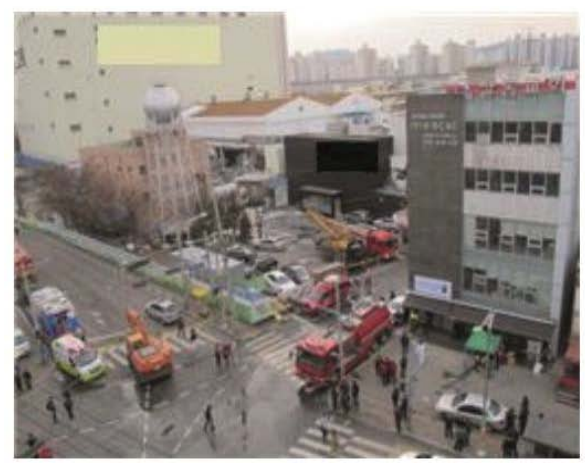

(b)

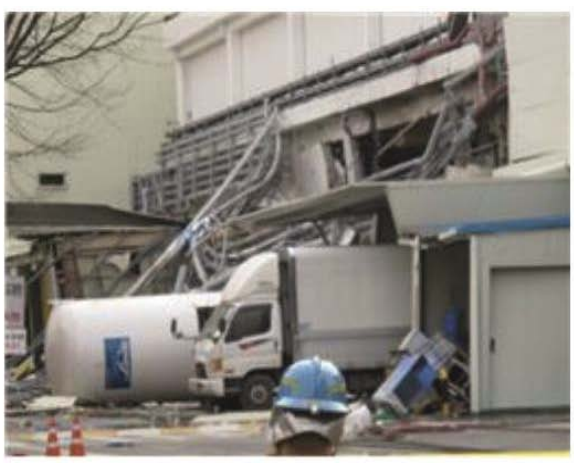

Fig. 1: a, b) Scene of the ammonia refrigeration facility explosion

experience eye irritation, headaches, etc. Medical checkups were recommended by the local authorities and in the week following the explosions, a total of 476 residents were evaluated (Anonymous, 2014).

Because ammonia gas is lighter than air (with a specific gravity of 0.59 ) and quickly disperses from the site of leaks, neighboring residents or workers can experience serious negative effects from ammonia inhalation but when ammonia gas is leaked in a confined space and cannot disperse, its can easily reach a concentration at which any source of ignition can cause an explosion despite its high LEL, causing large-scale damage.

To better understand the danger of ammonia gas leaks, this study demonstrates the hazardous characteristics of ammonia gas in confined spaces by simulating the overpressure range for an indoor ammonia leak scenario. The sequence of events as well as the leak and dispersion characteristics of the February, 2014 explosion are used to conduct simulations using the PHAST Software package to determine the likely gas concentration at the time of the explosion. This concentration is verified by comparing the observed and simulated levels of damage, providing information to support the concluded cause of the incident. Measures are then proposed to avoid future ammonia explosions in high-pressure refrigeration facilities.

\section{MATERIALS AND METHODS}

Method and scope of study: Existing studies on ammonia gas and the prediction of damage using risk assessment methods were reviewed. The investigation report of the Anonymous (2014) and the research report of the Korea Anonymous (2014) addressing the February, 2014 ammonia explosion accident were used to obtain the characteristics of the explosion. These characteristics were then used to create a PHAST Software simulation of the explosion severity and overpressure range, improving the understanding of the hazards presented by ammonia leaks and informing explosion prevention measures.

\section{Predicting accident damage}

Estimation of leakage velocity: The analysis of a release source consists of calculating the leakage velocity, leakage time and state of the released substance for the gas, liquid and gas liquid mixture phases. The data obtained is then used to predict the damage caused by an ensuing explosion. The driving force of any release is the pressure difference between the atmosphere and the released substance. The larger the difference, the faster the leakage velocity. The pressure of the released substance is based on its saturated vapor pressure and liquid head pressure at the compression, liquefaction and storage temperatures during the operation of the subject facility or storage process. When a substance is released from a facility into the air, if the pressure of the released substance is higher than the atmospheric pressure, the release is stated to have a chocked or critical flow (Van den Bosch and Weterings, 1997).

Liquid-state ammonia flows in the refrigerant coil of the unit cooler (evaporator) of a quick freezer. Accordingly, if any liquid-phase ammonia is released, the mechanical energy balance Eq. 1 can be applied to model the leakage:

$$
\int \frac{\mathrm{dP}}{\rho}+\Delta\left(\frac{\mathrm{u}^{2}}{2}\right)+\mathrm{g} \Delta \mathrm{z}+\mathrm{F}=-\frac{\mathrm{W}_{\mathrm{s}}}{\mathrm{m}}
$$

Where:
$\mathrm{P}=$ The Pressure of the stored liquid $(\mathrm{Pa})$
$\rho=$ The density of the stored liquid $\left(\mathrm{kg} / \mathrm{m}^{3}\right)$ 
$\mathrm{u}=$ The velocity of the stored liquid $(\mathrm{m} / \mathrm{sec})$

$\mathrm{g}=$ The gravitational acceleration $\left(9.81 \mathrm{~m} / \mathrm{sec}^{2}\right)$

$\mathrm{z}=$ The height from leak to the stored liquid (m)

$\mathrm{F}=$ The friction loss term $(\mathrm{mN} / \mathrm{kg})$

$\mathrm{Ws}=$ The shaft work $(\mathrm{nm})$

$\dot{\mathrm{m}}=$ The mass flux $(\mathrm{kg} / \mathrm{sec})$

It should be noted that as the set temperature of the quick freezer at the scene of the February, 2014 accident was $-30^{\circ} \mathrm{C}$ higher than the boiling point of ammonia the liquid-phase ammonia must have vaporized as soon as it was released. Because the density of an incompressible liquid is constant, the change in pressure $(\Delta \mathrm{P})$ can be expressed by:

$$
\int \frac{\mathrm{dP}}{\rho}=\frac{\Delta \mathrm{P}}{\rho}
$$

As shown in Fig. 2 because the pressure inside the refrigerant coil of the unit cooler (evaporator) is the gauge pressure $\left(\mathrm{P}_{\mathrm{g}}\right)$ and the external pressure is the atmospheric pressure in this case the change in pressure of the gas $\Delta \mathrm{P}=\mathrm{P}_{\mathrm{g}}$. When the refrigerant was released from the damaged part (hole) of the refrigerant coil of the unit cooler (evaporator), there was no change in liquid level. Accordingly, the value of $\Delta z$ was zero. If the shaft work and the flux in the unit cooler (evaporator) pipe are neglected, Eq. 1 can be expressed as:

$$
\frac{P_{0}}{\rho}+\frac{u^{2}}{2}+F=0
$$

The friction loss at leakage is then defined using the release coefficient $\mathrm{CD}$ as shown in Eq. 3:

$$
-\frac{\Delta \mathrm{P}}{\rho}-\mathrm{F}=\mathrm{C}_{\mathrm{D}}^{2}\left(-\frac{\Delta \mathrm{P}_{0}}{\rho}\right)
$$

which can be expressed as follows by applying $\Delta \mathrm{P}=\mathrm{P}_{\mathrm{g}}$ :

$$
-\frac{P_{0}}{\rho}-F=C_{D}^{2}\left(-\frac{P_{0}}{\rho}\right)
$$

The leakage velocity can then be calculated by combining Eq. 2 and 4 to yield:

$$
\mathrm{u}=\mathrm{C}_{\mathrm{D}} \sqrt{\frac{2 \mathrm{P}_{0}}{\rho}}
$$

Accordingly, the mass flux for the damaged area of the unit cooler refrigerant coil of a quick freezer can be expressed by Eq. 6:

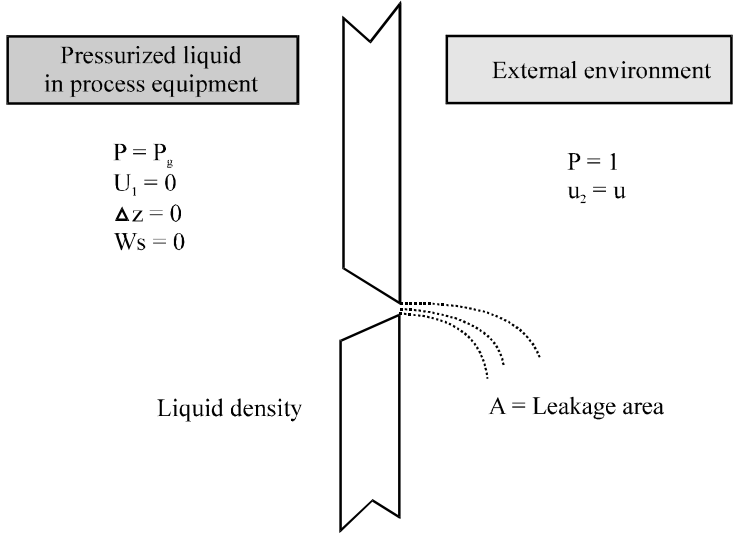

Fig. 2: Liquid release at the damaged region of freezing equipment

$$
\dot{\mathrm{Q}}=\rho \mu \mathrm{A}=\mathrm{AC}_{\mathrm{D}} \sqrt{2 \rho \mathrm{P}_{0}}
$$

Where:

$\dot{\mathrm{Q}}=$ The mass release rate of liquid $(\mathrm{kg} / \mathrm{sec})$

$\mathrm{A}=$ The area of the damage through which the liquid is leaked $\left(\mathrm{m}^{2}\right)$

Estimation of damage: Explosions can be divided into two types, physical explosions such as the bursting of high-pressure vessels and chemical explosions such as the combustion reaction of flammable substances. In most cases, chemical explosions occur due to rapid combustion in either a confined or open space. The potential progress routes of a chemical explosion due to release of a flammable substance is illustrated in Fig. 3.

Generally, chemical explosions attract interest because of the damage they cause by either shock wave overpressure or the ejection of fragments. When an explosion occurs as a result of a combustion reaction, the effect of the shock wave is particularly prominent. The degree of damage caused by an explosion is primarily determined by the following factors: the type and concentration of the flammable substance, the size and location of the flammable gas cloud, the location, intensity and type of ignition source, the number, size, direction and location of obstacles, the degree of confinement in the space where the substance is released and the size and location of any vents.

The chemical explosion of a substance in a confined space occurs as follows when a flammability condition is satisfied and an ignition source causes combustion, the propagation of flame (combustion wave) compresses the combustion wave due to the confining effects of the surrounding walls and the resulting rise in compressive wave pressure overpowers the strength of the walls, breaking them and causing damage. 


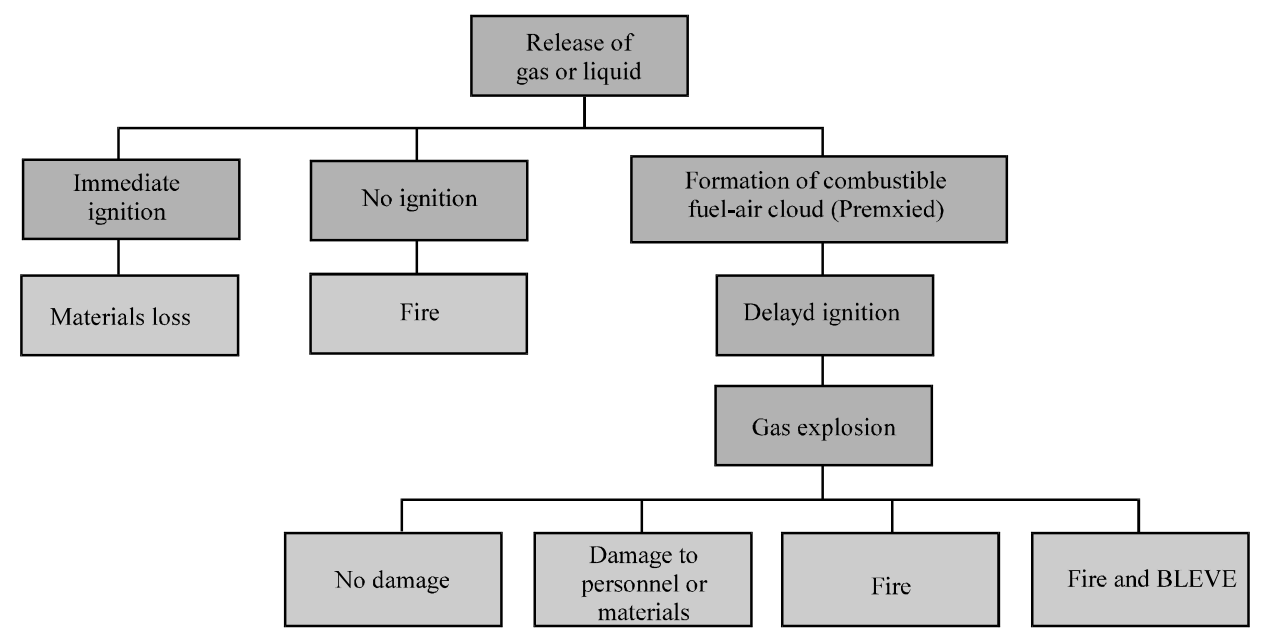

Fig. 3: Progress routes of explosion events

A blast wave is an air wave caused by explosion-induced movement dependent on the timeto-peak overpressure and includes a sonic compression wave, rarefaction wave, shock wave and compression wave (Sookyeong et al., 2011). Typically, the predominant components of a blast wave are the shock wave and the compression wave, propagated as strong winds in open air and including high pressure, density and particle velocity. The shock wave is caused by the rapid increase in pressure accompanying a drastic discharge of a large amount of energy while the compression wave requires a certain period of time to reach peak overpressure. A blast wave affects objects such as buildings in the form of side-on pressure and reflected pressure.

Side-on pressure is exerted on vertical faces in the direction of the blast wave propagation and is typically referred to as overpressure. Overpressure occurs in the positive phase of the blast wave and is so, named because it exceeds atmospheric pressure. The maximum pressure that occurs during the overpressure phase is called the peak pressure. Figure 4 depicts two typical blast wave profiles. In the case of a slow swelling of energy, the blast consists of gradually increasing pressure of small amplitude (Fig. 4a). In the case of a rapid swelling of energy, the blast shows a drastic increase in pressure, generating a shock wave (Fig. 4b).

The scale rule is applicable to the propagation of a blast wave. The blast characteristics of TNT which is widely used in military applications has been sufficiently established by a significant body of research, so, the blast characteristics of a flammable substance are typically quantified through conversion into TNT equivalence. Generally, the characteristics of a blast wave are expressed as a function of the scaled distance $\mathrm{Z}$ : once the TNT equivalent of the exploded flammable substance is calculated as per Eq. 7, the scaled distance to determine
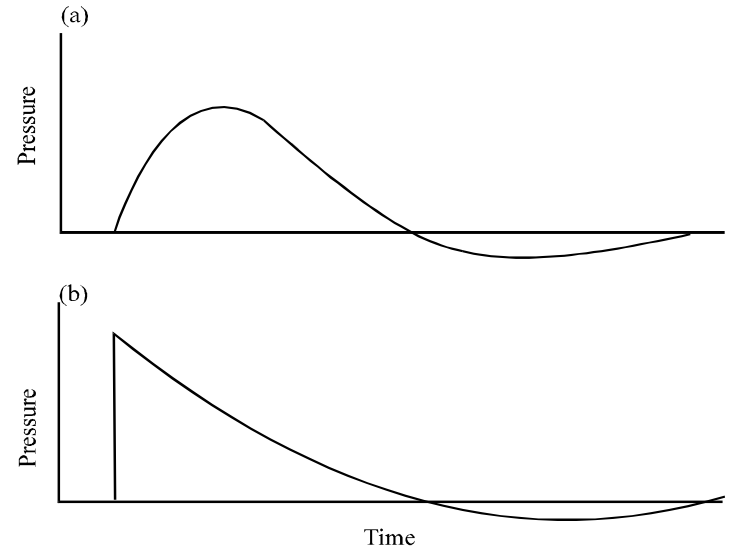

Fig. 4: a, b) Blast over pressure history

the force of the blast wave is obtained for the peak overpressure according to the equivalent TNT explosion using Eq. 8 (CCPS., 2010):

$$
\begin{gathered}
\mathrm{W}=\frac{(\eta) \mathrm{ME}_{\mathrm{c}}}{\mathrm{E}_{\mathrm{TNT}}} \\
\mathrm{Z}=\frac{\mathrm{R}}{\mathrm{W}^{1 / 3}}
\end{gathered}
$$

Where:

$\mathrm{W}=$ The TNT equivalent $(\mathrm{kg})$

$\mathrm{M}=$ The mass of the flammable substance $(\mathrm{kg})$, obtained by estimating gas release velocity and time

$\eta=$ The efficiency of the vapor cloud explosion, provided in Table 1

$E_{c}=$ The combustion heat of the flammable substance $(\mathrm{kJ} / \mathrm{kg})$ 
Table 1: Explosion efficiencies for flammable vapors and gases

\begin{tabular}{|c|c|c|c|}
\hline Explosion efficiency & & -Substance & \\
\hline$\eta=0.03$ & Acetaldehyde & Furfural alcohol & N-Butyl acetate \\
\hline & Acetone & Hydrocy anic acid & N-Decane \\
\hline & Acrylonitril & Hydrogen & N-Heptane \\
\hline & Amyl alcohol & Hydrogen sulphide & N-Hexane \\
\hline & Benzene & Iso-Butyl alcohol & N-Pentane \\
\hline & 1,3-Butadiene & Isobutylene & N-Propanol \\
\hline & Butene-1 & Iso-Octane & N-Propyl acetate \\
\hline & Carbon monoxide & Iso-Propyl alcohol & O-Dichlorobenzene \\
\hline & Cyanogen & Methalamine & P-Cymene \\
\hline & 1,1-Dichloroethane & Methane & Petroleum ether \\
\hline & 1,2-Dichloroethane & Methanol & Phthalic anhy dride \\
\hline & Dimethyl ether & Methyl acetate & Propane \\
\hline & Dimethyl sulphide & 3-Methyl-Butene-1 & Proprionaldehyde \\
\hline & Ethane & Methyl-butyl-Ketone & Propylene \\
\hline & Ethanol & Methyl Chloride & Propylene dichloride \\
\hline & Ethyl acetate & Methyl-Eutyl-Ketone & P-Xylene \\
\hline & Ethylamine & Methyl formate & Styrene \\
\hline & Ethyl benzene & Methyl Mercaptan & Tetrafluroethylene \\
\hline & Ethyl chloride & Methyl-Propyl-Ketone & Toluene \\
\hline & Ethyl cy clohexane & Monochlorobenzene & Vinyl acetate \\
\hline & Ethyl formate & N-Amyl acetate & Vinyl chloride \\
\hline & Ethyl proprionate & Naphthalene & Vinylidene chloride \\
\hline & & N-Butane & Water gas \\
\hline$\eta=0.06$ & Acrolein & Diethyl ether & Ethyl nitrate \\
\hline & Carbon Disulphide & Divinyl ether & Methyl-Vinyl-Ether \\
\hline & Cyclohexane & Ethylene & Propylene oxide \\
\hline$\eta=0.19$ & Acetylene & Hydrazine & Nitromethane \\
\hline & Ethy lene oxide & Isopropyl nitrate & Vinyl acetylene \\
\hline & Ethyl nitrate & Methyl acetylene & \\
\hline
\end{tabular}

Table 2: Overpressure damage estimates for common structures

Pressure

\begin{tabular}{|c|c|c|}
\hline psig & $\mathrm{kPa}$ & Damage estimates \\
\hline 0.02 & 0.14 & Annoying noise $(137 \mathrm{~dB}$ if low frequency $10-15 \mathrm{~Hz})$ \\
\hline 0.03 & 0.21 & Occasional breaking of large glass windows already under strain \\
\hline 0.04 & 0.28 & Loud noise $(143 \mathrm{~dB})$ sonic boom \\
\hline 0.1 & 0.69 & Breakage of small windows under strain \\
\hline 0.15 & 1.03 & Typical pressure for window breakage \\
\hline 0.3 & 2.07 & $\begin{array}{l}\text { "Safe distance (Probability } 0.95 \text { of no serious damage)", projectile limit, somedamage } \\
\text { tohouse ceilings; } 10 \% \text { window glass broken }\end{array}$ \\
\hline 0.4 & 2.76 & Limited minor structural damage \\
\hline $0.5-1.0$ & 3.4-6.9 & Large and small windows usually shattered, occasional damage towindow frames \\
\hline 0.7 & 4.8 & Minor damage to house structures \\
\hline 1.0 & 6.9 & Partial demolition of houses, made uninhabitable \\
\hline $1-2$ & $6.9-13.8$ & $\begin{array}{l}\text { Corrugated asbestos shattered, corrugated steelor aluminum panels, fast enings fail, } \\
\text { followed by buckling, wood panels fast enings fail, panels blown in }\end{array}$ \\
\hline 1.3 & 9.0 & Steel frames of masonry buildings slightly distorted \\
\hline 2 & 13.8 & Partial collapse of walls and roofs of houses \\
\hline $2-3$ & $13.8-20.7$ & Concrete or cinder block walls, not reinforced, shattered \\
\hline 2.3 & 15.8 & Lower limit of serious structural damage walls not reinforced, shattered \\
\hline 2.5 & 17.2 & $50 \%$ destruction of brick work of houses \\
\hline 3 & 20.7 & $\begin{array}{l}\text { Heavy machines }(3000 \mathrm{lb} \text {.) inindustrial building suffered little damage; steel frame } \\
\text { buildings distorted and pulled away from foundations }\end{array}$ \\
\hline $3-4$ & $20.7-27.6$ & Rupture of oil storage tanks, frameless, self-framing steel panel buildings demolished \\
\hline 4 & 27.6 & Cladding of light industrial buildings ruptured \\
\hline 5 & 34.5 & Wooden utility poles snapped, tall hydraulic press $(40,000 \mathrm{~b}$. $)$ in building slightly damaged \\
\hline $5-7$ & $34.5-48.2$ & Nearly complete destruction of houses \\
\hline 7 & 48.2 & Loaded train wagons overturned \\
\hline $7-8$ & $48.2-55.1$ & Brick panels, 8-12" in thick, no trein forced, fail by shearing or fracture \\
\hline 9 & 62.0 & Loaded train box cars completely demolished \\
\hline 10 & 68.9 & Probable total destruction of buildings; heavy machine tools $(7,0001 \mathrm{~b}$.) moved and badly damaged \\
\hline$\underline{300}$ & 2068 & Limit of crater lip \\
\hline
\end{tabular}

$\mathrm{E}_{\mathrm{TNT}}=$ The combustion heat of TNT $(46805 \mathrm{~kJ} / \mathrm{kg}$ or $1120 \mathrm{kcal} / \mathrm{kg}$ )

$\mathrm{Z}=$ The scaled distance $\left(\mathrm{m} / \mathrm{kg}^{1 / 3}\right)$

$\mathrm{R}=$ The distance of interest from the blast source (m)
The peak side-on overpressure $\left(\mathrm{P}_{\mathrm{s}}\right)$ at the scaled distance $(Z)$ can then be obtained from the graph in Fig. 5 (CCPS., 2010) with the corresponding estimated damage to a structure and other characteristics provided in Table 2 (Baker, 1973; Glasstone, 1962). In this study, 


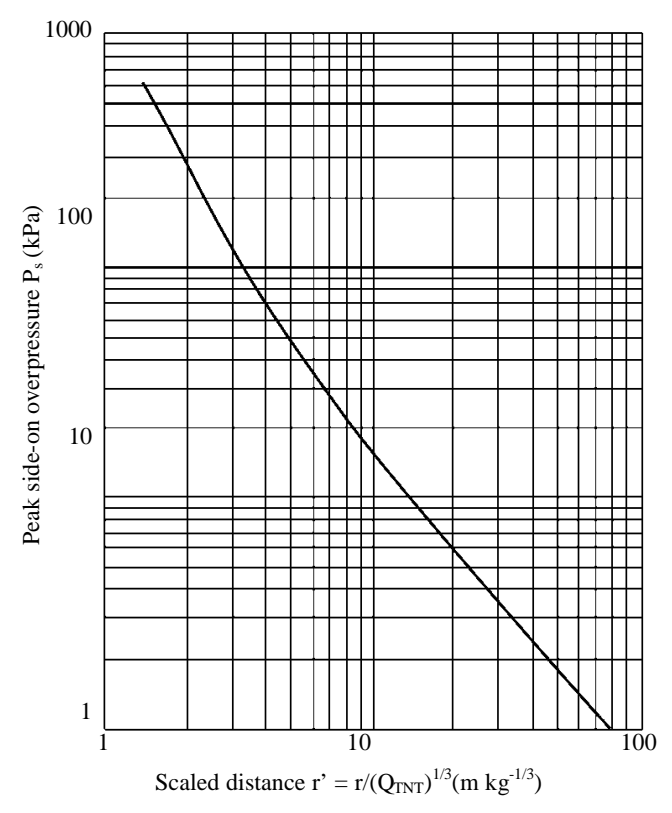

Fig. 5: Peak overpressure of TNT

the observed damage was correlated to a pressure of $48 \mathrm{kPa}$, corresponding to nearly complete destruction of houses and $69 \mathrm{kPa}$, corresponding to probable destruction of buildings for the evaluation of the severity of the subject explosion.

\section{Estimation of released and exploded gas}

Estimation of released gas using leakage velocity: Prior to the ignition of the February, 2014 explosion, ammonia gas was released when the refrigerant coil of the fan in the unit cooler installed in the quick freezer ruptured, creating a hole of about $1 \times 2 \mathrm{~cm}$. In the quick freezer, a surge tank was installed on the ceiling, $6 \mathrm{~m}$ above from the floor to transfer the ammonia gas refrigerant to the unit cooler. When the high-temperature and high-pressure $\left(25^{\circ} \mathrm{C}, 1 \mathrm{MPa}\right)$ liquid-phase ammonia gas passed through the expansion valve, it changed into its low-temperature and low-pressure liquid-phase $\left(-45^{\circ} \mathrm{C},-40 \mathrm{kPa}\right)$. After staying in the surge tank for a short time, the ammonia gas in the low-temperature and low-pressure liquid-phase flowed into the unit cooler through the insulated refrigerant coil pipe. As the ammonia gas flowed through the refrigerant coil of the unit cooler, the fan enhanced its ability to absorb the surrounding heat via. the latent heat of vaporization, lowering the temperature of the quick freezer below zero.

The temperature of the ammonia gas in the refrigerant coil of the unit cooler was $-45^{\circ} \mathrm{C}$ and its pressure was about $-40 \mathrm{kPa}(-300 \mathrm{mmHg})$. Accordingly, it can be estimated that even if the refrigerant coil of the unit cooler was damaged, the ammonia gas would not be immediately released. It was only once the pressure inside the refrigerant coil of the unit cooler became balanced with the atmospheric temperature inside the quick freezer that the gas release occurred. The typical operating pressure of the freezer during winter was $0.9 \mathrm{MPa}$. However, according to a worker at the facility on the day of the accident, the pressure gauge at the refrigeration machine room indicated an abnormally high pressure of $1.2 \mathrm{MPa}$ at 09:00 and the freezer was checked. The smell of ammonia gas was reported at 09:20. Using this information, it was estimated that the refrigerant coil of the unit cooler was damaged around 09:00 and the pressure in the refrigerant coil became balanced with the atmospheric pressure of the quick freezer within about $20 \mathrm{~min}$, causing the ammonia gas to be released around 09:20. At that time, the driving force of the ammonia gas release was the liquid static pressure of the liquefied ammonia gas stored in the surge tank installed on the ceiling of the quick freezer. The ammonia gas did not ignite and explode immediately after being leaked but rather seemed to have remained confined in the quick freezer for about $3 \mathrm{~h}$ and $45 \mathrm{~min}$, until 13:05 when the explosion occurred. Although, the exact time of the explosion was a little different among different investigative agencies and the media, this study has adopted 13:05 based on the time reported in the police investigation.

As ammonia has a boiling point of $-33.4^{\circ} \mathrm{C}$, it is easily vaporized in air. However, according to the testimony of a staff at the scene of accident, when the freezer was operated, the liquefied ammonia gas flowing in the unit cooler of the quick freezer had a temperature of $-45^{\circ} \mathrm{C}$ and the indoor temperature of the quick freezer was typically between -33 and $-30^{\circ} \mathrm{C}$, just above the boiling point of ammonia gas at $-33.5^{\circ} \mathrm{C}$. It was therefore, assumed that the liquefied ammonia released by the liquid static pressure in the surge tank was vaporized immediately upon release and Eq. 6 was applied to calculate the amount of released ammonia.

The discharge coefficient of ammonia gas at the damaged part of the refrigerant coil depends on the shape of the leak, defined by the release coefficient CD. This coefficient can vary between 0.6 and 0.9 but in the case of a common leak, 0.61 is conventionally applied (CCPS., 2010), so, this study also adopted 0.61. Because the gauge pressure inside the refrigerant coil was $-40 \mathrm{kPa}$ $(-300 \mathrm{~mm} \mathrm{Hg})$ when the refrigerant coil was broken, the ammonia gas was not released by the liquid static pressure in the surge tank until the pressure inside the refrigerant coil was balanced with the atmospheric pressure. Accordingly, to calculate the mass release rate of the ammonia gas, the change in the liquid static 
pressure of the liquefied ammonia gas in the surge tank, $3.55 \mathrm{~m}$ above the damaged refrigerant coil in the unit cooler was determined using Eq. 9:

$$
\Delta \mathrm{P} \frac{\rho g h}{\mathrm{~g}_{\mathrm{c}}}
$$

Where:

$\mathrm{g}_{\mathrm{c}}=$ The gravitational conversion factor $\left(\mathrm{kg} \cdot \mathrm{m} \cdot \mathrm{sec}^{-2} / \mathrm{N}\right)$ $\mathrm{h}=$ The height of the tank $(\mathrm{m})$

The change in liquid static pressure was then inserted into Eq. 6 to determine that the release rate of liquid ammonia gas was $0.729 \mathrm{~kg} / \mathrm{sec}$. Assuming a leakage duration of $3 \mathrm{~h}$ and $45 \mathrm{~min}$ (from 09:20-13:05), the amount of released ammonia gas was determined to be about $9841.5 \mathrm{~kg}$.

However, the upper and lower liquid surface heights of the surge tank were typically set at one-third full and two-thirds full, respectively. An electronic valve installed at the surge tank inlet was opened to supply ammonia gas when the liquid surface height was below the lower limit. If the liquid surface height reached the upper limit an alarm was sounded and an operator manually cut off the injection of gas. According to a staff working at the refrigeration facility when a smell of ammonia gas was detected on the day of the accident, the refrigerant pipe supplying ammonia to the surge tank of the quick freezer was shut off. Therefore, because the surge tank had an internal capacity of $2238 \mathrm{~L}$ and the freezer was typically operated with the liquid surface height indicating one-third full, the amount of ammonia gas in one surge tank was estimated to be $545.18 \mathrm{~kg}$ and because the two surge tanks were connected to each other through a suction pipe, total amount of the ammonia gas able to be released from two surge tanks was estimated to be $1090.36 \mathrm{~kg}$. Taken together, this information indicates that the $9841.5 \mathrm{~kg}$ of ammonia gas mathematically estimated to have been released over the $3.75 \mathrm{~h}$ of leakage is quite unreasonable.

Therefore, the ammonia gas could not have been continuously released over $3.75 \mathrm{~h}$ from 09:20 at which time the staff perceived the smell of ammonia to 13:05 at which time the explosion occurred. Dividing the amount of liquid ammonia gas stored in the two surge tanks by the liquid release rate at the damaged part of the unit cooler refrigerant coil determined in Eq. 9 and 6, the duration of the ammonia gas leakage was calculated to have been about $25 \mathrm{~min}$.

Estimation of gas dispersion from sequence of events: As no ammonia gas remained in the two surge tanks in the quick freezer, the full $1090.36 \mathrm{~kg}$ of stored ammonia gas was released. However, not all of the released ammonia gas exploded: the total amount of ammonia gas released into the confines of the quick freezer is equivalent to a volume of $1,282.78 \mathrm{~m}^{3}$, corresponding to a concentration of $69 \%$ concentration which far exceeds the UEL of $28 \%$. According to worker testimony, the $2.6-\mathrm{m}$ high, $1.4-\mathrm{m}$ wide heat-resistant door between the quick freezer and the front room was totally opened and the $2.6-\mathrm{m}$ high, $2.5 \mathrm{~m}$ wide main entrance door on the yard side of the freezer was opened about $1 \mathrm{~m}$ from 10:00-13:05 on the day of accident in order to discharge the leaked ammonia gas. As shown in Fig. 6-8, a ventilator with a capacity of $38 \mathrm{~m}^{3} / \mathrm{min}$ (corresponding to a $0.538 \mathrm{~kg} / \mathrm{sec}$ release rate of ammonia gas), suction pipe and a discharge pipe were installed in the quick freezer to assist in this discharge. Under these ventilation conditions, it would

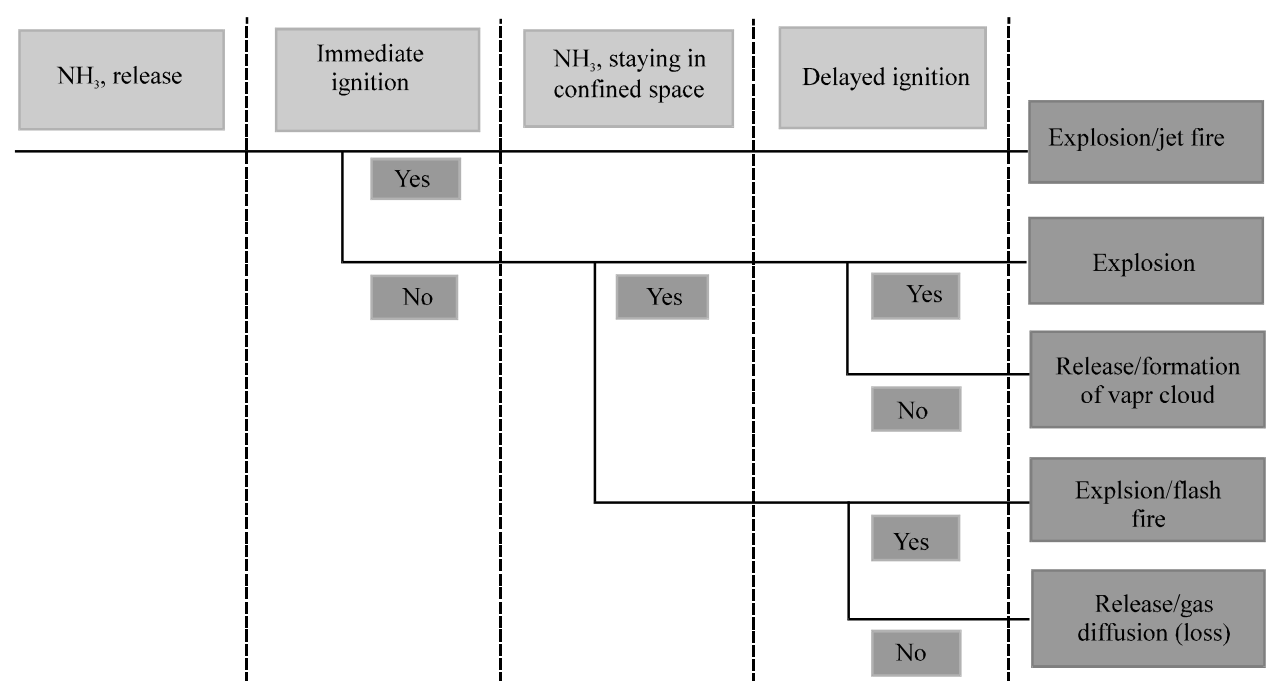

Fig. 6: Flow chart of potential ammonia leak outcomes 


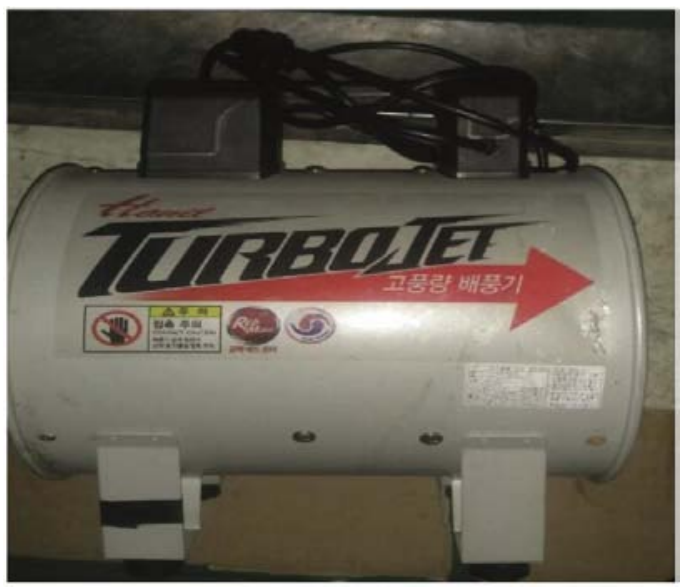

Fig. 7: Ventilator used for ammonia gas discharge

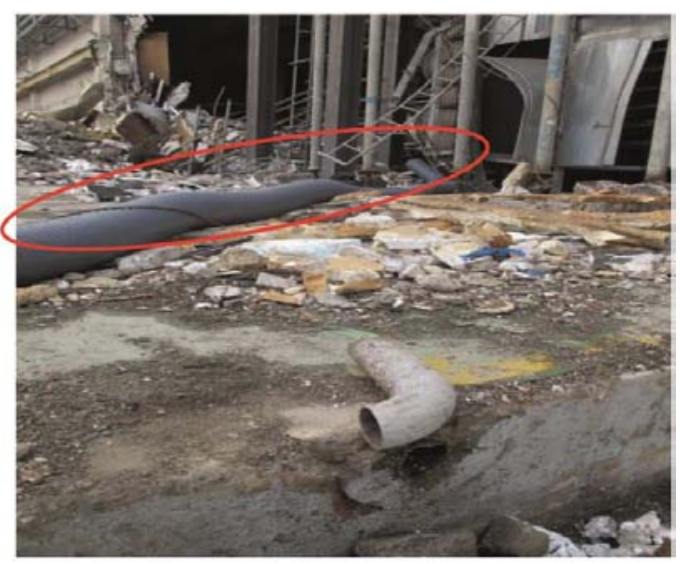

Fig. 8: Tube used for ammonia gas discharge

theoretically take about $33.76 \mathrm{~min}$ to completely discharge the $1282.78 \mathrm{~m}^{3}$ of released ammonia gas using only the local ventilation device and no explosion could have occurred after 10:34. However, because the gas discharge work was done at the bottom of the quick freezer and given the working and ventilation efficiency of the local ventilator, the time required for complete discharge of ammonia gas increased. Consequently, as the released ammonia gas was discharged from the quick freezer, the concentration of gas remaining in the freezer was eventually reduced to within the explosive range and then exploded due to an ignition source such as the non-explosion proof unit cooler fan or sensors such as the thermometer interlock that always, continuously generated an electric spark during operation.

Based on the elapsed time between the initial release and the explosion of the ammonia gas in the quick freezer, it can be inferred that about 1.09 tons $\left(1283 \mathrm{~m}^{3}\right)$ of ammonia gas was vaporized from the liquid phase and released from the surge tanks for about $25 \mathrm{~min}$ from 09:20 to $09: 45$ on the day of accident and remained in the quick freezer at a concentration of about $69 \%$ far higher than the UEL (28\%). As the ammonia gas was discharged from 10:00-13:05, the concentration of the gas decreased into the explosive range and the explosion occurred.

Estimation of available gas present at the explosion using the explosive range: The quick freezer in which the ammonia gas exploded was $16.48 \mathrm{~m}$ wide, $9.64 \mathrm{~m}$ long and $6.80 \mathrm{~m}$ high. Each of the two unit coolers installed in the quick freezer were $5.30 \mathrm{~m}$ wide, $1.05 \mathrm{~m}$ long and $3.03 \mathrm{~m}$ high. There were two conveyers for moving products through the freezer each $6.25 \mathrm{~m}$ wide, $6.25 \mathrm{~m}$ long and $6.00 \mathrm{~m}$ high. The two surge tanks for the refrigerant gas were each $0.965 \mathrm{~m}$ in diameter and $3.47 \mathrm{~m}$ long. Once the volumes of the unit coolers, conveyers and surge tanks were removed, the total volume of the quick freezer that could be occupied by ammonia gas prior to the explosion was calculated to be about $572.75 \mathrm{~m}^{3}$. Based on this volume and the explosive range of ammonia gas (15-28\% in air), the theoretical amount of ammonia gas that was available to fuel an explosion in the quick freezer was estimated. Using the LEL $(15 \%)$, the theoretical minimum volume of gas available was calculated to be $101.07 \mathrm{~m}^{3}$ as follows:

$$
15 \%(\text { lower explosion })=\frac{x}{x+572.75} \times 100
$$

(where, $\mathrm{x}=$ Ammonia explosion amount)

$$
\mathrm{x}=\frac{0.15 \times 572.75}{0.85}=101.07 \mathrm{~m}^{3}
$$

Similarly, using the UEL (28\%), the theoretical maximum volume of gas was calculated to be $222.74 \mathrm{~m}^{3}$. Because the indoor temperature of the quick freezer was between -33 and $-30^{\circ} \mathrm{C}$ and given that the density of ammonia gas at its boiling point of $-33.4^{\circ} \mathrm{C}$ is $0.86 \mathrm{~kg} / \mathrm{m}^{3}$ and at around $-30^{\circ} \mathrm{C}$ is $0.85 \mathrm{~kg} / \mathrm{m}^{3}$ (Anonymous, 2005) the theoretical mass of ammonia gas available to fuel an explosion in the quick freezer was estimated to be in the range of $85.91-189.33 \mathrm{~kg}$.

\section{RESULTS AND DISCUSSION}

Analysis of explosion: In the PHAST Software, the explosion of the ammonia gas in the quick freezer was approximated as an explosion in a tank and the danger of the ammonia gas was examined in relation to the point 


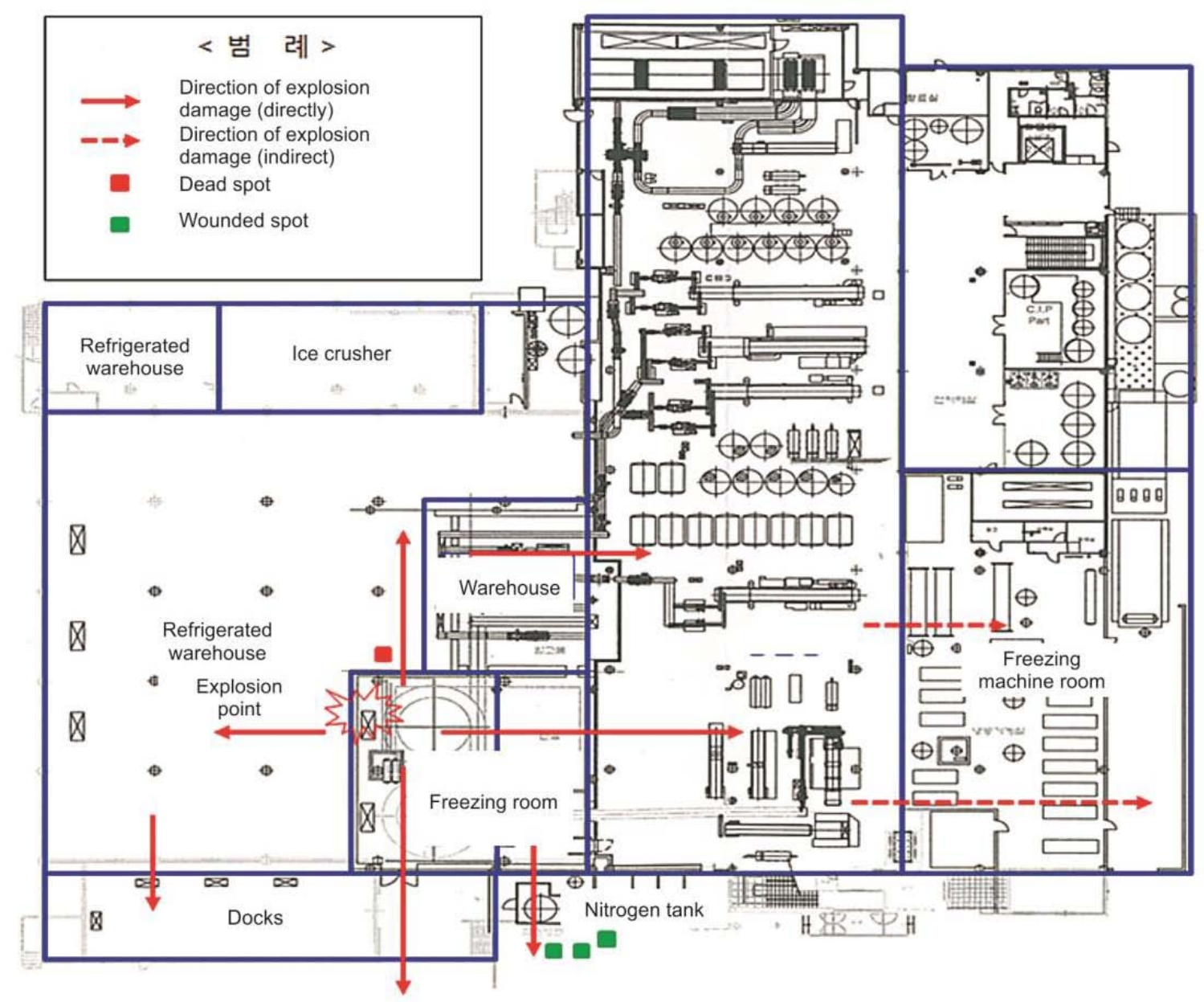

Fig. 9: Plant equipment layout and explosion direction at the scene of the accident

within the explosive range at which the ammonia gas could have exploded. Applying different theoretical masses of ammonia gas in the previously determined explosive range of 85.91-189.33 kg, a simulation was conducted to determine at which point in the explosive range sufficient overpressure would be developed to break down the walls as observed in the aftermath of the February, 2014 explosion.

Selection of accident scenario: The PHAST program is not able to vary the concentration of ammonia gas over time and the specific rates of indoor leakage could not be verified. Instead, different concentrations of ammonia gas within the explosive range were assumed and the effects of an explosion at these concentrations were compared with the observed damage. Figure 9 illustrates the layout of the equipment in the refrigeration facility. The quick freezer of the refrigeration facility was built of $20-30 \mathrm{~cm}$ thick brick walls. The explosion was observed to have destroyed all of these surrounding brick walls not only those surrounding the quick freezer about $0.8 \mathrm{~m}$ away from the explosion point but also those of the front room, which were about $16 \mathrm{~m}$ away. Additionally, a 14.5 ton liquid nitrogen tank in front of the front room and outside the quick freezer was toppled. The refrigeration machine room, about $44.5 \mathrm{~m}$ away from the quick freezer, exhibited damage to the steel beams. This damage was assumed to be consistent with an overpressure of $48 \mathrm{kPa}$, corresponding to nearly complete destruction of houses, and $69 \mathrm{kPa}$, corresponding to probable destruction of buildings as shown in Table 2 . The damage indicated by the results at each gas concentration level using the PHAST program were compared against the observed damage to determine the likely concentration of ammonia gas in the quick freezer at the time of the explosion.

Analysis of results: When the theoretical upper limit of $189 \mathrm{~kg}$ of gas was used to simulate the dispersion state of 


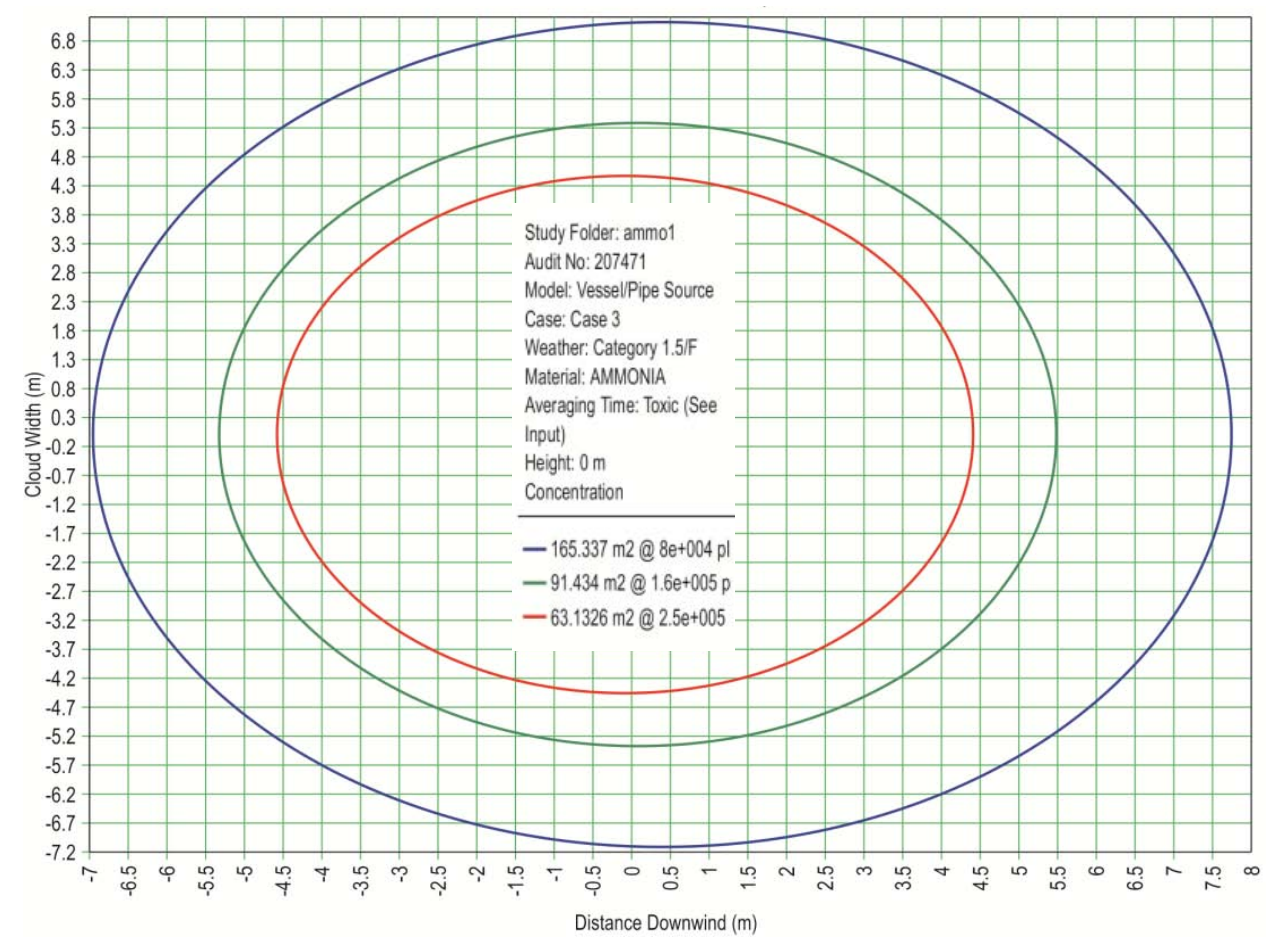

Fig. 10: Explosive range of $189 \mathrm{~kg}$ of ammonia gas; Maximum concentration footpoint

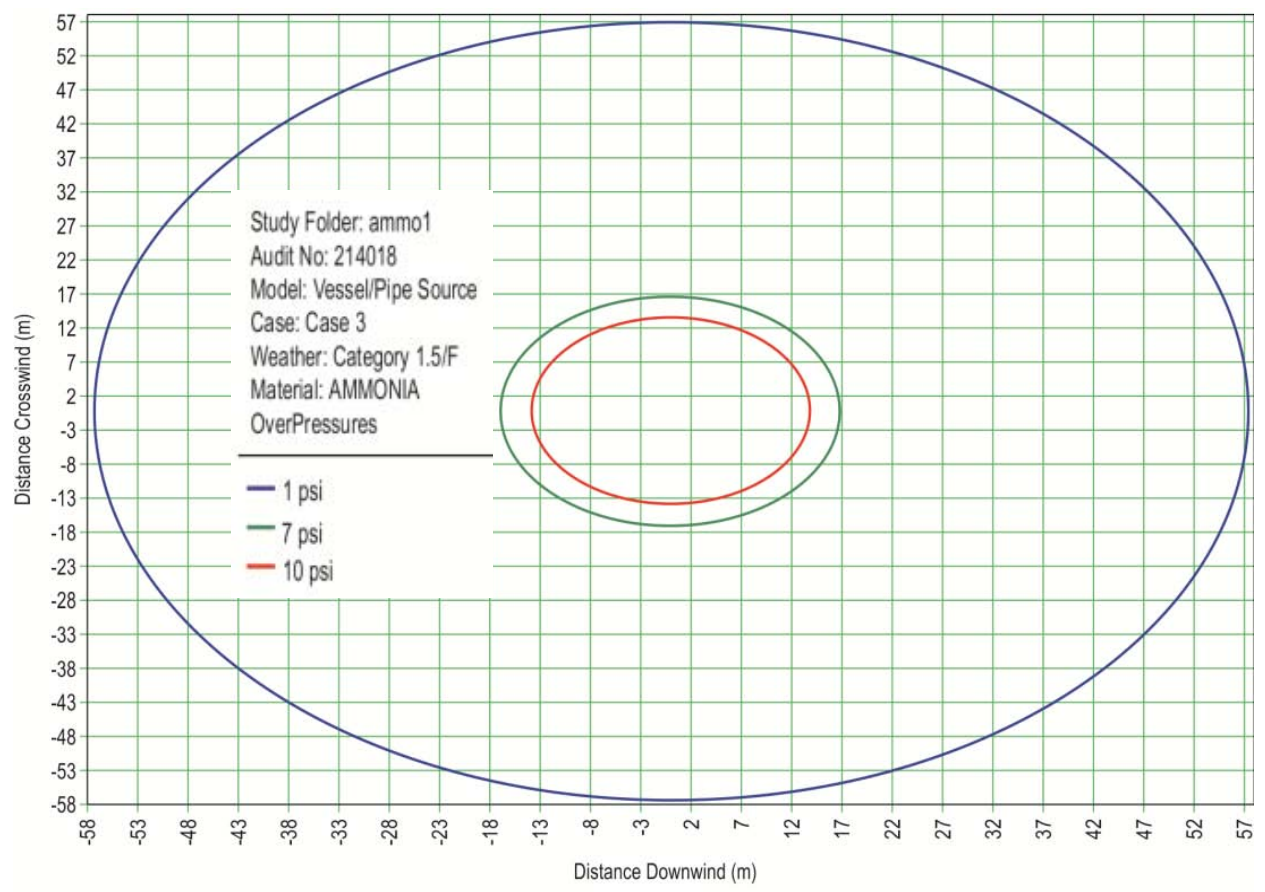

Fig. 11: Overpressure radii of $189 \mathrm{~kg}$ of ammonia gas; Early explosion overpressure radii

ammonia gas, the explosive range at the UEL of $250,000 \mathrm{ppm}$ and at LEL of $160,000 \mathrm{ppm}$ was determined to be $4.68-5.69 \mathrm{~m}$ as shown in Fig. 10 which was well within the area of the quick freezer. The overpressure radii of the explosion, shown in Fig 11 at 7 psi was $16.84 \mathrm{~m}$ and at 10 psi was $13.72 \mathrm{~m}$. Therefore, the simulation verified that 


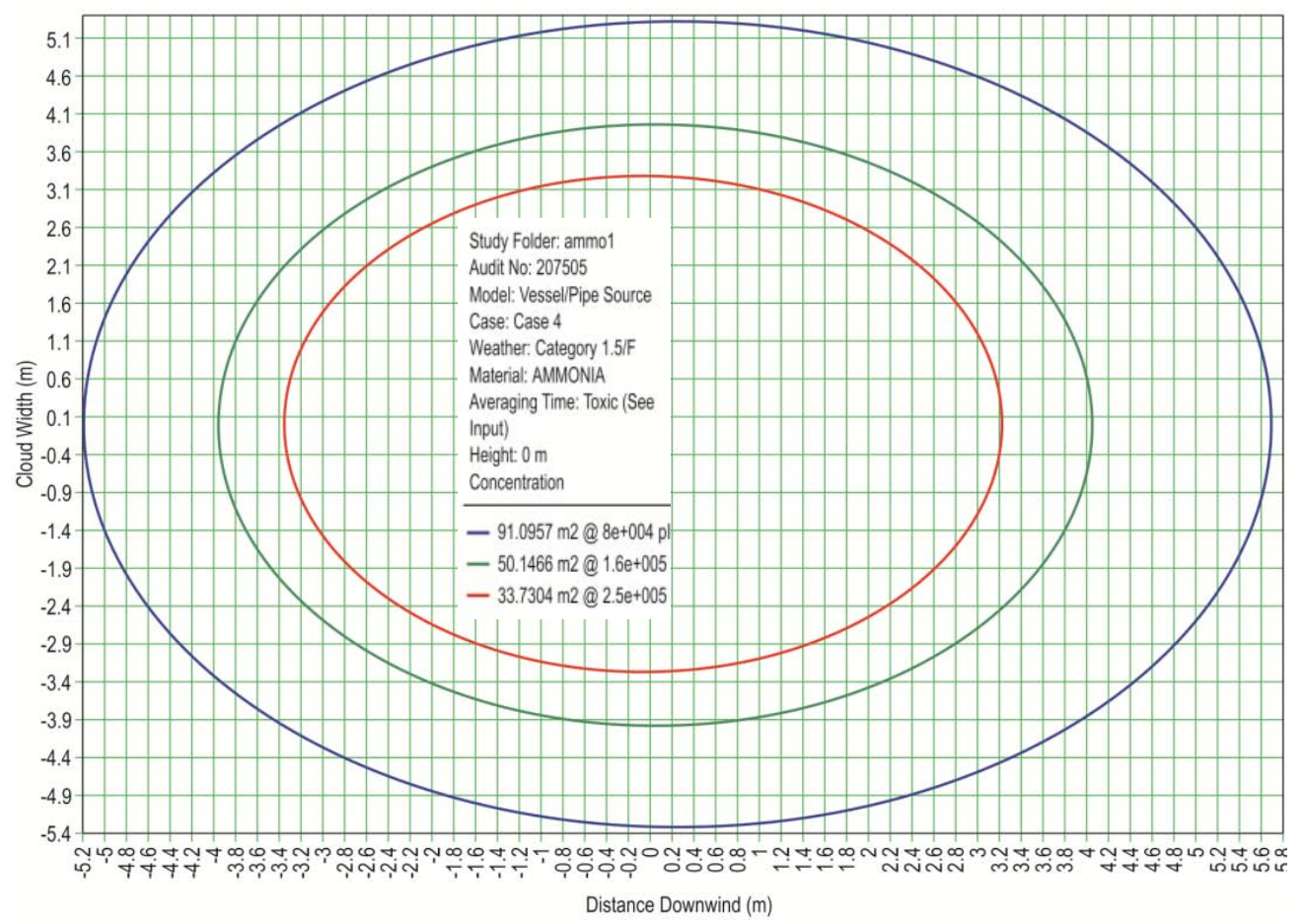

Fig. 12: Explosive range of $86 \mathrm{~kg}$ of ammonia gas; Maximum concentration footpoint

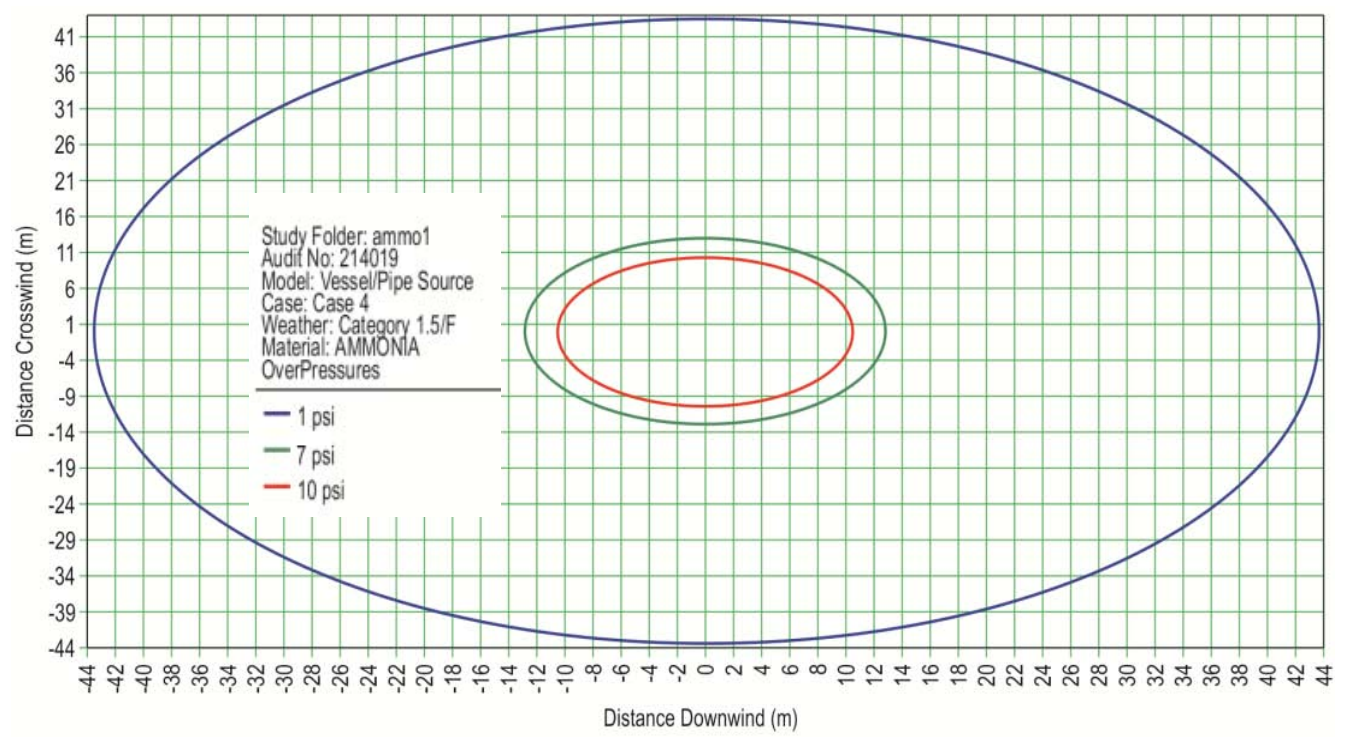

Fig. 13: Overpressure radii of $86 \mathrm{~kg}$ of ammonia gas; Early explosion overpressure radii

the theoretically determined upper limit of released ammonia gas was sufficient to generate the observed damage.

When the theoretical lower limit of $85.913 \mathrm{~kg}$ of gas was used to simulate the dispersion states of ammonia gas, the explosive range for a UEL $250,000 \mathrm{ppm}$ and an LEL of 160,000 ppm was determined to be $3.47-4.20 \mathrm{~m}$, shown in Fig. 12, well within the area of the quick freezer. The overpressure radii of the explosion, shown in Fig. 13, at $7 \mathrm{psi}$ was $12.8 \mathrm{~m}$ and at $10 \mathrm{psi}$ was $10.43 \mathrm{~m}$. These values are too small to cause the damage observed from the February, 2014 explosion, indicating that the concentration of ammonia gas was likely closer to the upper limit of the explosive range. 
Therefore, when the ammonia gas was released, it was initially too highly concentrated to explode, even in the presence of an ignition source. The gas was then slowly vented and dispersed and its concentration slowly decreased to the upper limit of its explosive range of $28 \%$ at which time the explosion was initiation by a pre-existing ignition source. The explosion damage estimates determined using the PHAST program were found to be in good agreement with the observed damage at the upper limit of the explosive range, further supporting the conclusion that it was during the venting of the ammonia gas that the explosion occurred.

\section{CONCLUSION}

This study analyzed the sequence of events and observed damage caused by an ammonia refrigerant gas explosion in February, 2014 at a high-pressure refrigeration facility in Namyangju-si, Gyeonggi-do to estimate the amount of ammonia gas released. The characteristics of the facility and the dispersion of the gas with respect to the sequence of events were accounted for mathematically to determine an expected range of ammonia gas concentration at the time of the explosion. Damage was then numerically simulated with respect to these explosive concentration limits using the PHAST program and compared to the observed damage to determine the likely quantity of ammonia and the likely cause of the explosion. The study indicated that when ammonia gas is used as a refrigerant in high-pressure refrigeration facilities, the release of this gas into the confined space of a quick freezer can result in sufficient concentrations within its explosive limits, creating the dangerous possibility of an explosion. As a result of this danger, several measures to prevent ammonia gas explosions in high-pressure refrigeration facilities are proposed as follows:

Because ammonia gas released into a confined space like a quick freezer was found to readily reach its explosive range, the ammonia gas equipment installed indoors in a high-pressure refrigeration facility should be equipped with explosion proof electrical equipment and a forced ventilation system installed in the upper portion of the indoor space. If emergency ventilation is required, it must be conducted in the upper portion of the indoor space, where ammonia gas concentrations are likely the highest. To minimize the loss of life due to ammonia gas-related fire or explosions, every high-pressure refrigeration facility should be equipped with a communication system to notify all employee's of a dangerous situation and help all employees (including those of subcontractors) quickly evacuate and take other appropriate measures.

The February, 2014 ammonia gas explosion revealed that faulty procedures such as discharging ammonia gas from the bottom of a confined space, directly contributed to the explosion. Current procedures and regulations concerning the prevention of ammonia explosion accidents in a high-pressure refrigeration facility, therefore, need to be deeply examined and revised. The understanding of the mechanics of ammonia gas leakage, dispersion and response provided by this study can be used to improve these procedures and regulations, helping to better prevent ammonia gas explosions.

\section{ACKNOWLEDGEMENT}

I would like to thank my beloved family and professor Lee Suk-kyung for helping me to complete this study. No funding was received for this study.

\section{REFERENCES}

Anonymous, 2005. Ammonia-NH3-thermodynamic properties. Engineering ToolBox, New York, USA.

Anonymous, 2014. Case study on refrigerator ammonia leakage and explosion. Korea Occupational Safety and Health Agency, Ulsan, South Korea.

Baker, W.E., 1973. Explosions in Air. University of Texas Press, Austin, Texas, USA.,.

CCPS., 2010. Guidelines for Chemical Process Quantitative Risk Analysis (CPQRA). 2nd Edn., Wiley-Interscience, New York, USA., ISBN: 9780470935422, Pages: 784.

Glasstone, S., 1962. The Effects of Nuclear Weapons. US Atomic Energy Commission, Washington DC., USA., Pages: 730 .

Sookyeong, L., Y. Jeong, J. Joeng, H. Dongmyung and C. Gumnan, 2011. An Introduction to Combustion. Donghwa Technology Publishing, Seoul, South Korea, Pages: 267.

Van den Bosch, C.J.H. and R.A.P.M. Weterings, 1997. Methods for the Calculation of Physical Effects (CPR 14E). 3rd Edn., Publicatiereeks Gevaarlijke Stoffen, The Netherlands, Pages: 870. 